\title{
TRAMADOL AS AN ADJUNCT TO BUPIVACAINE FOR BRACHIAL PLEXUS BLOCK.
}

\footnotetext{
1. FCPS Anesthesiology Senior Registrar Department of Anesthesia, Ch. Pervaiz Elahi Institute of Cardiology, Multan.

2. FCPS Anesthesiology Senior Registrar Department of Anesthesia Nishtar Medical University, Multan.

3. FCPS Anesthesiology

Consultant

Department of Anesthesia King Khalid Hospital, Saudi Arabia.

4. FCPS (Cardiology)

Assistant Professor

Department of Cardiology University Medical \& Dental College Faisalabad.
}

\section{Correspondence Address:}

Dr. Afifa Zahoor

Zahoor Villa Kotla Waris Shah

Chungi Number 1, Multan.

afifazahoor@gmail.com

Article received on:

05/03/2019

Accepted for publication:

25/06/2019

Received after proof reading:

$28 / 08 / 2019$

\section{INTRODUCTION}

Post-operative pain is always very unpleasant to the patient and is always of major concern for anesthetist and surgeons. Therefore, optimum pain management is done relieve anxiety, and uneasiness of the patients. ${ }^{1}$ Upper extremity surgery can be performed by employing various techniques like general anaesthesia, intra venous regional anaesthesia and local nerve blocks. Brachial plexus block (BPB) is now a widely used technique adopted by anesthesiologist for surgeries involving the upper limb and for acute pain management. ${ }^{2}$ BPB is advantageous when compared with general anesthesia, because it provides better pain control, no side effects as with general anesthesia and llonger control of post-op pain. ${ }^{3}$ However, the duration of block is only 8 hours to 14 hours even with the use of longer half-life local anesthetics. ${ }^{4}$ Many adjuvants have been searched to extend the analgesic efficacy and to reduce adverse outcomes of local anesthesia such as perineural magnesium, dexmedetomidine, clonidine, dexamethasone and tramadol. ${ }^{2,5-8}$

Use of tramadol as oral or parenteral is now proven effective for post-op management of pain. ${ }^{9}$ Tramadol minimizes pain using two different pathways; opioid like action mediated by action of $\mu$ receptors and $2^{\text {nd }}$ one mediated by its $a_{2}$-adrenergic and serotoninergic activity. ${ }^{10,11}$ Tramadol mainly inhibits descending pain pathways and hence prevents transmission of nociceptive signals to spinal cord. ${ }^{12}$

There is still an ongoing debate either the use of Tramadol as an adjunct to bupivacaine for BPB is beneficial or it do not have any protective effects. ${ }^{13-15}$ So in present study we in present study we evaluated the efficacy of Tramadol as an adjunct to bupivacaine for BPB in patients undergoing upper extremity orthopedic 
procedures.

\section{METHODOLOGY}

This randomized controlled trial was arranged in the orthopedic department of Nishtar Medical University/Hospital Multan. Permission of study was obtained from hospital IRB department. The study duration was Jan-2018 to Aug-2018.

Informed consent was taken from the attendants and patients, describing them objective and procedure of this study. They were briefed that there will be no harm to the patient and the confidentiality of your personal information will always be maintained.

Cases were selected from orthopedic department, Nishtar Hospital, Multan. Pre-operative visit was done a day before operation. Patients with upper limb surgeries meeting the inclusion criteria were included in the study. All patients were premedicated with half tablet lexilium $3 \mathrm{mg}$ a night before operation.

Patients were randomly allocated into two equal clusters by lottery method. Patients were asked to pick $A$ or $B$.

Group A were given solution with $38 \mathrm{ml} 0.25 \%$ bupivacaine with $100 \mathrm{mg}$ tramadol $2 \mathrm{ml}$.

Group B was given solution with $38 \mathrm{ml} 0.25 \%$ bupivacaine and $2 \mathrm{ml} 0.9 \%$ normal saline.

Before starting the procedure, $18 \mathrm{G}$ venous cannula was passed in the opposite hand of selected patients and routine monitors were attached like pulse oximeter, blood pressure cuff, ECG electrodes.

Supraclavicular BPB was performed in all patients in supine position with head bowed to opposite side. A 22 G (1.5 inch) needle was inserted just $2 \mathrm{~cm}$ above the midclavicular part and moved towards the subclavian artery until patients encountered paresthesia. $40 \mathrm{ml}$ of local anaesthetic (Inj. bupivacaine $0.25 \%$ ) with or without tramadol was injected in this area. Sensory block was tested by alcohol swabs.
Patients were given oxygen through mask and vitals monitoring (pulse, respiratory rate, blood pressure) and to monitor study outcomes for 30 minutes (at 5-minute interval) after that interval was increased to 10 minutes until the procedure ends. Time of onset of analgesia and time of injection of local anaesthetic was noted.

Throughout operation, patients were checked for any side effects and complications like respiratory distress, pneumothorax and seizures. All the observations were recorded and entered in the Proforma specifically designed for the study by the researcher. Time for requirement of first rescue analgesia was noted and entered in the Performa and thus duration of analgesia was measured. Bias, if any, was controlled by standardization of measurement technique.

For data analysis we used SPSS v23 software. For comparing the quantitative variables between the groups, we used independent sample t-test. While for comparing the qualitative data we used Chi-square test. P-value $<0.05$ was considered significant.

\section{RESULTS}

There were 148 patients in total. Mean age of the patients was $41.82 \pm 13.67$ years $(41.51 \pm 13.50$ years in group $A$ versus $42.14+13.92$ years in group $B, p$-value 0.78$)$ ). Males were $81 / 148$ (54.7\%) [39 (52.7\% in group A \& 42 (56.8\%) in group B], while females were $67 / 128$ (45.3\%) [35 (47.3\%) in group A \& 32 (43.2\%) in group B, p-value 0.62]. Mean weight of the patients was $57.50 \pm 11.50 \mathrm{Kg}(56.45 \pm 10.52 \mathrm{Kg}$ in group A versus $58.55 \pm 12.13 \mathrm{Kg}$ in group $\mathrm{B}, \mathrm{p}$-value 0.26 ) Table-I.

Time of onset of block was $14.56 \pm 1.01$ minutes in group A versus 15.96 \pm 1.64 minutes in group $B$ ( $p$-value <0.001). Mean analgesia duration was $355.85 \pm 42.18$ minutes in group $A$ versus $310.47 \pm 38.79$ minutes in group $B$ ( $p$-value $<0.001)$. There were $51(68.9 \%)$ patients in group A who required rescue analgesia and 68 (91.9\%) patients in group B required rescue analgesia (p-value 0.004) Table-II. 


\begin{tabular}{|c|c|c|c|}
\hline & $\begin{array}{l}\text { Tramadol group (A) } \\
(n=74)\end{array}$ & $\begin{array}{c}\text { Control group (B) } \\
(n=74)\end{array}$ & P-value \\
\hline Mean age (years) & $41.51 \pm 13.50$ & $42.14 \pm 13.92$ & 0.78 \\
\hline Male gender & $39(52.7 \%)$ & $42(56.8 \%)$ & \multirow{2}{*}{0.62} \\
\hline Female gender & $35(47.3 \%)$ & $32(43.2 \%)$ & \\
\hline Mean weight $(\mathrm{kg})$ & $56.45 \pm 10.52$ & $58.55 \pm 12.13$ & 0.26 \\
\hline \multicolumn{4}{|c|}{ Table-I. General characteristics of the patients. } \\
\hline & $\begin{array}{l}\text { Tramadol group (A) } \\
(n=74)\end{array}$ & $\begin{array}{c}\text { Control group (B) } \\
(n=74)\end{array}$ & P-value \\
\hline Onset of block (min) & $14.56 \pm 1.01$ & $15.96 \pm 1.63$ & $<0.001$ \\
\hline Mean duration of analgesia & $355.85 \pm 42.18$ & $310.47 \pm 38.79$ & $<0.001$ \\
\hline Need for Analgesia & $51(68.9 \%)$ & $68(91.9 \%)$ & 0.004 \\
\hline
\end{tabular}

\section{DISCUSSION}

The use of BPB has become a routine practice in orthopedic procedures because it provides excellent surgical environment with very little discomfort and complications for surgeries involving the arm and forearm. ${ }^{16}$ Bupivacaine is a commonest drug for induction of BPB, and can alone provide analgesia for a reasonable time margin. ${ }^{17}$ Additives are added to bupivacaine to increase the duration of block induced by bupivacaine. In present study we added tramadol along with bupivacaine for BPB and evaluated its effects on time of block onset, duration of analgesia and need for rescue analgesics. We found a significant positive effects of tramadol addition, as it enhances the early onset of block, provides longer duration of analgesia and reduces the rescue analgesics requirements.

Common adverse effects of tramadol administration are sedation, dizziness, nausea, vomiting and headache. These adverse effects are lower when tramadol is given for BPB as compared to its intra-venous regimens. ${ }^{18}$

A study conducted by Khosa et al. reported similar results. They found shorter time of block onset, $16.20 \pm .96$ minutes in tramadol versus $17.3 \pm 1.49$ minutes in control group. they also reported longer duration of block $6.9 \pm 0.76$ hours in tramadol versus $4.7 \pm 1.07$ hours in control group. ${ }^{19}$

Kesimci et al. conducted a similar study by using ropivacaine for BPB using tramadol as adjuvant. The authors reported no benefit of addition of tramadol. They found mean bock time $631 \pm 33$ min in tramadol versus $633 \pm 37 \mathrm{~min}$ in control group. ${ }^{15}$

Kaabchi et al. reported late onset of block using tramadol for BPB. They concluded that the longer duration is countered by slow onset so there is no benefit of adding tramadol for $\mathrm{BP}^{20}$ However these authors used lidocaine as a primary drug for induction of BPB and we used bupivacaine as a primary drug.

Another study by Sarcu et al. failed to found any significant beneficial effects of addition of tramadol and axillary plexus block in-terms of need for rescue analgesics, satisfaction score and VAS score during the procedure. ${ }^{21}$

A recent meta-analysis by Shin et al. on effectiveness of tramadol (100 mg) as adjunct to local anesthetic drugs concluded that the addition of tramadol is associated with early onset of sensory and motor block, it prolongs the duration of analgesia and reduces the requirement of rescue analgesics. But it did not reduce the adverse effects associated with $\mathrm{BPB}$ in these patients. ${ }^{2}$

\section{CONCLUSION}

In present study, we concluded that the addition of tramadol as adjunct to bupivacaine for BPB significantly shortens the duration of onset, 
prolongs the duration of analgesia and reduces the need for rescue analgesics.

Copyright $\subset 25$ June, 2019.

\section{REFERENCES}

1. Brennan F, Carr DB, Cousins M. Pain management: A fundamental human right. Anesthe Analg. 2007; 105(1):205-21.

2. Shin HW, Ju BJ, Jang YK, You HS, Kang H, Park JY. Effect of tramadol as an adjuvant to local anesthetics for brachial plexus block: A systematic review and meta-analysis. PloS one. 2017; 12(9):e0184649.

3. Richman JM, Liu SS, Courpas G, Wong R, Rowlingson AJ, McGready J, et al. Does continuous peripheral nerve block provide superior pain control to opioids? A meta-analysis. Anesth Analg. 2006; 102(1):248-57.

4. Fritsch $\mathrm{G}$, Danninger $\mathrm{T}$, Allerberger $\mathrm{K}$, Tsodikov $\mathrm{A}$, Felder TK, Kapeller M, et al. Dexmedetomidine added to ropivacaine extends the duration of interscalene brachial plexus blocks for elective shoulder surgery when compared with ropivacaine alone: $A$ single-center, prospective, triple-blind, randomized controlled trial. Reg Anesth Pain Med. 2014; 39(1):3747

5. Mukherjee K, Das A, Basunia SR, Dutta S, Mandal $P$, Mukherjee $A$. Evaluation of magnesium as an adjuvant in ropivacaine-induced supraclavicular brachial plexus block: A prospective, double-blinded randomized controlled study. J Res Pharmacy Pract. $2014 ; 3(4): 123$.

6. Abdallah F, Brull R. Facilitatory effects of perineural dexmedetomidine on neuraxial and peripheral nerve block: a systematic review and meta-analysis. $\mathrm{Br} \mathrm{J}$ Anaesth. 2013; 110(6):915-25.

7. Pöpping DM, Elia N, Marret E, Wenk M, Tramer MR. Clonidine as an adjuvant to local anesthetics for peripheral nerve and plexus blocksa meta-analysis of randomized trials. Anesthesiology. 2009; 111(2):40615.

8. Knezevic NN, Anantamongkol U, Candido KD. Perineural dexamethasone added to local anesthesia for brachial plexus block improves pain but delays block onset and motor blockade recovery. Pain Physician. 2015; 18(1):1-14.

9. Miotto K, Cho AK, Khalil MA, Blanco K, Sasaki JD, Rawson R. Trends in tramadol: Pharmacology, metabolism, and misuse. Anesth Analg. 2017; 124(1):44-51.

10. Grond S, Sablotzki A. Clinical pharmacology of tramadol. Clin Pharmacokinet. 2004; 43(13):879-923.
11. Kayser V, Besson J-M, Guilbaud G. Evidence for a noradrenergic component in the antinociceptive effect of the analgesic agent tramadol in an animal model of clinical pain, the arthritic rat. Eur $J$ Pharmacol. 1992; 224(1):83-8.

12. Arcioni $R$, della Rocca $M$, Romanò $S$, Romano $R$, Pietropaoli P, Gasparetto A. Ondansetron inhibits the analgesic effects of tramadol: A possible 5-HT3 spinal receptor involvement in acute pain in humans. Anesth Analg. 2002; 94(6):1553-7.

13. Nagpal V, Rana S, Singh J, Chaudhary SK. Comparative study of systemically and perineurally administered tramadol as an adjunct for supraclavicular brachial plexus block. J Anaesthesiol Clin Pharmacol. 2015; $31(2): 191-5$.

14. Trabelsi W, Lebbi A, Romdhani C, Naas I, Sammoud W, Elaskri H. Dexamethasone provides longer analgesia than tramadol when added to lidocaine after ultrasound guided supraclavicular brachial plexus block. A randomized, controlled, double blinded study. Analg Resusc. 2013; 2:1-6.

15. Kesimci E, Izdes S, Gozdemir M, Kanbak O. Tramadol does not prolong the effect of ropivacaine $7.5 \mathrm{mg} / \mathrm{ml}$ for axillary brachial plexus block. Acta Anaesthesiol Scand. 2007; 51(6):736-41.

16. Albrecht E, Mermoud J, Fournier N, Kern C, Kirkham K. A systematic review of ultrasound $\square$ guided methods for brachial plexus blockade. Anaesthesia. 2016; $71(2): 213-27$

17. Cox C, Checketts M, Mackenzie N, Scott N, Bannister $J$. Comparison of $S(-)$-bupivacaine with racemic (RS)-bupivacaine in supraclavicular brachial plexus block. Br J Anaesth. 1998; 80(5):594-8.

18. Kirksey MA, Haskins SC, Cheng J, Liu SS. Local anesthetic peripheral nerve block adjuvants for prolongation of analgesia: A systematic qualitative review. PloS one. 2015; 10(9):e0137312.

19. Khosa $\mathrm{AH}$, Asad N, Durrani H. Does the addition of Tramadol to local anaesthetic mixture improve the quality of axillary brachial plexus block: A comparative study at the teaching hospital, Dera Ghazi Khan. PJHMS. 2015; 9(4):1120-3.

20. Kaabachi O, Ouezini R, Koubaa W, Ghrab B, Zargouni $A, A b d e l a z i z A B$. Tramadol as an adjuvant to lidocaine for axillary brachial plexus block. Anesth Analg. 2009; 108(1):367-70.

21. Sarsu S, Mizrak A, Karakurum G. Tramadol use for axillary brachial plexus blockade. J Surg Res. 2011; 165(1):e23-e7. 


\section{AUTHORSHIP AND CONTRIBUTION DECLARATION}

\begin{tabular}{|c|c|c|c|}
\hline Sr. \# & Author-s Full Name & Contribution to the paper & Author $=\mathbf{s}$ Signature \\
\hline 1 & Afifa Zahoor & $\begin{array}{l}\text { Conceived, designed, data analysis } \\
\text { and editing of manuscript. }\end{array}$ & \\
\hline 2 & Ranna Mussrat & $\begin{array}{l}\text { Did data collection and manuscript } \\
\text { writing. }\end{array}$ & \\
\hline 3 & $\begin{array}{l}\text { M. Ahmad Khan } \\
\text { Shakeel Ahmad }\end{array}$ & $\begin{array}{l}\text { Helped in writing the manuscript and } \\
\text { did review and approved the final } \\
\text { version for publication. } \\
\text { Co-Author }\end{array}$ & \\
\hline
\end{tabular}

